\title{
RESEARCHING CULTURE AND HEALTH: VARIABLES USED TO IDENTIFY CULTURALLY DIVERSE GROUPS IN NEW SOUTH WALES
}

\section{Tim Luckett}

School of Occupation and Leisure Sciences

University of Sydney

\section{Ilse Blignault}

School of Public Health and Community Medicine \&

Muru Marri Indigenous Health Unit

University of New South Wales

\section{Maurice Eisenbruch}

Institute for Health and Diversity

Victoria University

NSW is one of Australia's most multicultural states, with 29 per cent of residents having been born overseas and 24 per cent speaking a language other than English at home. ${ }^{1}$ Given that rates of death and disease and patterns of health service utilisation differ across cultural variables such as region or country of birth ${ }^{2,3}$, a better understanding of the interactions between culture and health may enable public health programs and clinical services to be more sensitive to community needs.

To help build in NSW the research capacity to identify cultural and linguistic diversity it is useful to first describe the current practice of health research in this area. A description of the data that are currently collected and how this is used would establish whether current research practice is consistent with national guidelines. In addition, the strengths and weaknesses of available information could be determined, especially its utility for allowing comparisons across studies.

In 1999 the Australian Bureau of Statistics (ABS) released Standards for Statistics on Cultural and Language Diversity. ${ }^{4}$ The Standards include a Minimum Core Set and a larger Standard Set of diversity variables (see Box 1). While a recent review has looked at the collection of diversity data in national health and community datasets ${ }^{9}$, little is known about the way the ABS sets or other variables are being used by individual health researchers in NSW or the rest of Australia.

Here, we present findings from a cross-sectional survey that provides a snapshot of data collected in health research with a cultural component in NSW. We were especially interested to find out which of the variables included in the Minimum Core Set or Standard Set were most commonly used by researchers, and whether these recommended variables were used alone or in combination with others.

\section{METHOD}

In October 2004 a letter of invitation enclosing an information sheet and questionnaire were emailed to 650 individuals who were identified either as likely to be carrying out health research with a cultural component in NSW or as holding a position that would enable them to circulate the material among likely participants. Recipients were requested to return completed questionnaires by email attachment and to also forward the invitation to colleagues who might be engaged in relevant research. 'Cultural component' was defined as relating to ethnicity, language or religion, with the exception of research exclusively concerned with the health of Aboriginal and Torres Strait Islander peoples.

Researchers were identified through searches of publication databases and lists of researchers awarded funding for projects in the area of culture and health from the National Health and Medical Research Council or Australian

\section{BOX 1}

\section{MINIMUM CORE SET AND STANDARD SETS OF DIVERSITY VARIABLES}

The Standards for Statistics on Cultural and Linguistic Diversity ${ }^{4}$ set out standards to identify, define, classify and disseminate particular attributes of a person or group that relate to their origins and cultural and language background, and outline methods for their use in statistical, administrative and service provision settings. The standards provide governments, academics and private sector organisations with a consistent way of identifying, measuring and monitoring service needs associated with advantage or disadvantage related to cultural background. Several of the standards make reference to major Australian standard classifications concerned with language and cultural diversity. ${ }^{5-8}$ In 1999 the Council of Ministers of Immigration and Multicultural Affairs recommended that the following minimum core set of variables be implemented in all commonwealth, state and territory statistical and administrative collections that require information on cultural and language diversity:

- Country of Birth of Person

- Main Language Other than English Spoken at Home

- Proficiency in Spoken English

- Indigenous Status.

This Minimum Core Set is drawn from a Standard Set that also includes:

- Country of Birth of Mother

- Country of Birth of Father

- First Language Spoken

- Languages Spoken at Home

- Main Languages Spoken at Home

- Ancestry

- Religious Affiliation

- Year of Arrival in Australia. 
Research Council between January 2000 and October 2004. Others contacted included the staff of health research centres in NSW and at health-related faculties, schools or departments at all the universities in NSW; personnel at statewide multicultural health services (for example the NSW Refugee Health Service); and the heads of multicultural health services, public health units and research and development bodies in all area health services. Initial contacts were followed up after a week

\section{TABLE 1}

\section{FREQUENCY WITH WHICH DIVERSITY VARIABLES WERE INCLUDED IN RESPONDENTS' DATASETS $(\mathrm{N}=119)$}

\begin{tabular}{|lcc|}
\hline Variable & $\boldsymbol{n}$ & $\%$ \\
\hline Country of Birth & 97 & 82 \\
Main Language Spoken at Home & 62 & 52 \\
Year of Arrival in Australia & 51 & 43 \\
Main Language Other Than English & 50 & 42 \\
Spoken at Home & & \\
Proficiency in Spoken English & 43 & 36 \\
Languages Spoken at Home & 41 & 34 \\
Country of Birth of Mother & 38 & 32 \\
Country of Birth of Father & 37 & 31 \\
Indigenous Status & 37 & 31 \\
First Language Spoken & 28 & 24 \\
Religious Affiliation & 26 & 22 \\
Ancestry & 19 & 16 \\
Ethnicity* & 11 & 9 \\
\hline * Also 'ethnic background', 'ethnic or cultural background' or \\
'ethnic group identity'
\end{tabular}

with a reminder email, and again by a second email a week later.

The four-page questionnaire included both open-ended items and closed items. The items covered respondents' broad research interests, any research they had conducted with a cultural component, how they defined their samples, and the cultural variables on which they collected data (including a request to indicate each of the Standard Set of diversity variables employed).

\section{RESULTS}

One hundred and nineteen surveys were returned. Of the 148 researchers who were identified through publications and grants searches, 31 (21 per cent) returned surveys. Just over half the respondents (55 per cent) named a university as their main workplace, with the rest identifying a principal role in the health service, with or without a conjoint appointment at an academic institution. Public health and/or health promotion were the most common disciplines, followed by psychology/psycho-oncology and epidemiology.

Table 1 describes the frequency with which individual cultural diversity variables were used by researchers, while Table 2 describes the frequency with which two or more variables were used in combination.

\section{DISCUSSION}

While not representative of the practice of health researchers in NSW generally, the survey results, which are almost equally divided between academic and practice-based

\section{TABLE 2}

COMBINATIONS OF CULTURAL AND LINGUISTIC DIVERSITY VARIABLES USED BY RESPONDENTS (N=119)

\begin{tabular}{|c|c|c|c|}
\hline \multirow{2}{*}{$\begin{array}{l}\text { Variables used } \\
\qquad n\end{array}$} & \multicolumn{2}{|c|}{ Researchers } & \multirow[t]{2}{*}{ Examples } \\
\hline & $n$ & $\%$ & \\
\hline 2 & 8 & 7 & $\begin{array}{l}\text { COB, MLSH } \\
\text { COB, LSH }\end{array}$ \\
\hline 3 & 17 & 14 & $\begin{array}{l}\text { COB, IS, YOA } \\
\text { COB, MLOTESH, MLSH }\end{array}$ \\
\hline 4 & 18 & 15 & $\begin{array}{l}\text { COB, COB father, COB mother, YOA } \\
\text { COB, MLSH, IS, RA }\end{array}$ \\
\hline 5 & 10 & 8 & $\begin{array}{l}\text { COB, MLSH, FLS, PSE, YOA } \\
\text { COB, IS, A, RA, YOA }\end{array}$ \\
\hline 6 & 14 & 12 & $\begin{array}{l}\text { COB, COB father, COB mother, MLSH, PSE, RA } \\
\text { COB, MLOTESH, MLSH, LSH, IS, YOA }\end{array}$ \\
\hline 7 & 10 & 8 & $\begin{array}{l}\text { COB, MLOTESH, MLSH, LSH, FLS, A, RA, } \\
\text { COB, COB mother, COB father, PSE, IS, A, YOA }\end{array}$ \\
\hline 8 & 9 & 8 & $\begin{array}{l}\text { COB, COB father, COB mother, MLSH, PSE, IS, RA, YOA } \\
\text { COB, MLOTESH, MLSH, LSH, FLS, PSE, RA, YOA }\end{array}$ \\
\hline 9 & 6 & 5 & $\begin{array}{l}\text { COB, COB father, COB mother, MLOTESH, MLSH, FLS, LSH, RA, YOA } \\
\text { COB, COB father, COB mother, MLSH, LSH, FLS, PSE, IS, YOA }\end{array}$ \\
\hline 10 & 2 & 2 & COB, COB father, COB mother, MLOTESH, MLSH, LSH, FLS, PSE, RA, YOA \\
\hline 11 & 2 & 2 & COB, COB father, COB mother, MLOTESH, MLSH, LSH, FLS, PSE, IS, RA, YOA \\
\hline 12 & 1 & 1 & COB, COB father, COB mother, MLOTESH, MLSH, LSH, FLS, PSE, IS, A, RA, YOA \\
\hline $\begin{array}{l}\text { A }=A \\
\text { Home } \\
\text { Profic }\end{array}$ & try & un & $\begin{array}{l}\text { rth; IS = Indigenous Status; FLS = First Language Spoken; LSH = Languages Spoken at } \\
\text { oken at Home; MLOTESH = Main Language Other than English Spoken at Home; PSE = } \\
\text { = Religious Affiliation; YOA = Year of Arrival in Australia }\end{array}$ \\
\hline
\end{tabular}


research and include responses from a broad cross-section of disciplines, provide a useful snapshot of research with a cultural component in NSW. The relatively low response rate by authors of publications and grants may have been due, in part, to the retrospective nature of the study. A current and major interest in culture and health research would likely have been a motivating factor in deciding to participate.

The most frequently used diversity variable was 'Country of Birth'; this is also the variable most commonly featured in Australia's national datasets. ' 'Country of Birth' provides information about origin and enables ready comparison with census and overseas data. However, when used on its own, this variable fails to identify cultural groups who belong to minority groups in their countries of origin. ${ }^{4}$ It was encouraging, then, to find a strong preference in the present sample for collecting cultural data across more than one variable. Variables in combination capture disproportionately more information than any single item. However, only one researcher made use of the full Standard Set of diversity variables, and only a handful used the Minimum Core Set, with or without additions from the Standard Set or elsewhere. 'Ancestry' was infrequently used, perhaps because it is a poor indicator of service needs and possibly as a result of a perception that many Australians feel no strong identification with a non-proximal heritage. ${ }^{4}$

The majority of respondents chose to collect data on three or four variables. This may have been thought to represent a balance in cost-benefit, where increases in the burden placed on the participants are weighed against the benefits of gaining more information. ${ }^{10}$ The most popular combination was 'Country of Birth', one of the language variables and 'Year of Arrival in Australia', which may have been favoured as an estimate of familiarity with Australian services. 'Period of Residence', a more accurate measure of time spent in Australia, was never reported, although it may have been calculated from 'Year of Arrival'. Interestingly, 'Proficiency in Spoken English'- the best predictor from the Standard Set of socio-economic status and the most powerful indicator of service needs ${ }^{4}$ — was only ever used as part of a larger set of variables. It is not known whether researchers included other more direct measures of socioeconomic status.

Data was also collected by the current sample on a range of variables not included in the Standard Set. The most common of these was 'Ethnicity', variously construed as 'Ethnic Background', 'Ethnic or Cultural Background' or 'Ethnic Group Identity'. 'Ethnicity', like 'Ancestry', is potentially problematic as a research variable because of its highly subjective and changeable nature. ${ }^{11}$ More information is needed on how health researchers assess cultural self-identification and how they apply this concept in their research.
Another point of concern relates to respondents' frequent use of the term 'non-English speaking background' when describing samples. The ABS has recommended that nonEnglish speaking background should no longer be used as a general purpose indicator due to its many conflicting definitions, its failure to identify disadvantaged groups or to capture the diversity of Australia's cultural and linguistic groups, and its negative connotations. ${ }^{4}$ Even when making comparisons between research carried out with similar populations, the reviewer needs to be wary of subtle differences between criteria used to define samples. 'Vietnamese-speaking', for example, refers to a different population than that described by 'Vietnamborn', 'Vietnamese-Australian' or simply 'Vietnamese', all of which featured as descriptions of samples on returned surveys.

A number of researchers pointed to proficiency in written or spoken English as being a requirement for completing the surveys/questionnaires they used, or for giving informed consent. Exclusion of whole groups from health research that aims to be representative is a matter of concern from both ethical and methodological perspectives. ${ }^{12}$

\section{CONCLUSION}

Given the need for more information about the way that interactions between cultural and other demographic and socio-economic factors influence health and wellbeing, it is essential to have high quality representative data on culturally diverse groups. With its rich cultural diversity, NSW has an opportunity to set the standard in conducting research with culturally diverse populations to ensure accurate representation. This paper summarises the diversity data collected by health researchers carrying out work in this field. Encouragingly, most researchers used combinations of variables rather than single variables on their own; however, few used the Sets of diversity variables recommended by the ABS. Further research should focus on the purposes to which researchers are putting different variables, especially highly subjective variables such as those pertaining to ethnicity.

\section{ACKNOWLEDGEMENTS}

The authors would like to thank the Sax Institute (formerly the Institute for Health Research) for providing the funds necessary to carry out this work; they would also like to thank all the researchers who contributed to the survey.

The research reported in this article was carried out while all three authors were employed at the Centre for Culture and Health, University of New South Wales.

\section{REFERENCES}

1. Australian Bureau of Statistics. 2001 census of population and housing. Summary data available on website of Federation of Ethnic Communities Council at www.fecca.org.au/Resources/ census/IndexNSW.html. Accessed 6 January 2006. 
2. Draper G, Turrell G \& Oldenburg B. Health inequalities in Australia - Mortality. Canberra, Queensland University of Technology and the Australian Institute of Health and Welfare. Health Inequalities Monitoring Series No. 1. AIHW Cat. No. PHE 55. Canberra: AIHW; 2004.

3. Population Health Division. The health of the people of New South Wales - Report of the Chief Health Officer. Sydney: NSW Department of Health; 2004.

4. Australian Bureau of Statistics. Standards for statistics on cultural and linguistic diversity. ABS Cat. No. 1289.0. Canberra: ABS; 1999.

5. Australian Bureau of Statistics. Australian standard classification of religious groups (ASCRG). ABS Cat. No. 1266.0. Canberra: ABS; 1996.

6. Australian Bureau of Statistics. Australian standard classification of languages (ASCL). ABS Cat. No. 1267.0. Canberra: ABS; 1997

7. Australian Bureau of Statistics. Standard Australian classification of countries (SACC). ABS Cat. No. 1269.0. Canberra: ABS; 1998.
8. Australian Bureau of Statistics. Australian standard classification of cultural and ethnic groups. ABS Cat. No. 1249.0. Canberra: ABS; 2000.

9. Blignault I, Haghshenas A. Identification of Australians from culturally and linguistically diverse backgrounds in national health data collections. Aust Health Rev 2005; 29 (4): 455-68.

10. Cunningham J.A, Ansara D, Wild T.C, Toneatto T, KoskiJannes A. What is the price of perfection? The hidden costs of using detailed assessment instruments to measure alcohol consumption. J Stud Alcohol 1999; 60(6): 756-8.

11. Waters M. Race and ethnicity. National Institute of Child Health and Human Development. Available at www.nichd. nih.gov/about/cpr/dbs/sp/waters1.htm, accessed 6 January 2006.

12. Ashcroft RE, Chadwick DW, Clark SR, Edwards RH, Frith L, Hutton JL. Implications of socio-cultural contexts for the ethics of clinical trials, Health Technol Assess 1997; 1(9): i-65. 욤

\section{GETTING A 'GRIPP’ ON THE RESEARCH-POLICY INTERFACE IN NEW SOUTH WALES}

The Sax Institute, Sydney

The Sax Institute is a coalition of over 30 universities and research centres across NSW. The Institute is funded by NSW Health to improve health outcomes and services by building policy and practice focused research and increasing the impact of this research on health policy, programs and services. The Institute's 'Getting Research into Policy and Practice' (GRIPP) program was established to develop new models for linking research with policy and practice. This report outlines the background to the development of the GRIPP program and describes some of the program's key achievements to date.

\section{GETTING STARTED: WHAT DID WE KNOW?}

The lack of connection between research and policy and practice is widely acknowledged. Studies conducted with policy decision makers suggest that limited contact with researchers and a lack of timeliness or relevance of research results can act as barriers to the use of research evidence in policy development. ${ }^{1,2}$ Researchers in academic environments also face obstacles. For example, their incentive system emphasises publication in peer-reviewed journals over broader knowledge-transfer activities. ${ }^{3,4}$ Possibly the greatest challenge is understanding that research is one of many competing forms of 'evidence' in policy making. Political and economic realities and information from a variety of sources, such as reports and expert opinion, also influence policy decision making. ${ }^{5}$

Several models for improving research and practice links have been trialled. The Canadian Health Services Research Foundation, for example, has developed a collaborative knowledge exchange program to facilitate the planning, dissemination, and application of research in healthcare decision making. However, while these models provide useful descriptive information about research translation strategies, there remains very little evidence about what works in practice.

\section{GETTING STARTED: WHAT DID WE DO?}

Against this background the GRIPP committee was established in 2003. The committee was a conjoint venture between the Institute and NSW Health, initially co-chaired by Dr Greg Stewart (then NSW Chief Health Officer) and Professor Anthony Zwi (from the University of NSW). Members included senior policy makers from the NSW Department of Health and the area health services along with leading population health and health services researchers. In mapping out an initial direction for the GRIPP program, the committee sought to explore current perceptions and practice relevant to evidence-informed policy; implement a systematic approach to setting policy-relevant research priorities; and trial a range of new approaches to improving the conduct of policy-relevant research and the dissemination of findings through the health system. 